Reseña

\section{Didier Boisseuil, David Igual Luis y María Martínez Alcalde (eds). Los alumbres españoles y mediterráneos en la Europa del siglo xv e inicios del xv. Producción, usos y distribución de una materia prima. Madrid, Consejo Superior de Investigaciones Científicas, 2020, 235 pp. ISBN: 978-8400107154.}

El volumen reúne varios estudios en torno a la producción, el negocio, la demanda y las técnicas relacionadas con los usos que tenía el alumbre en las épocas medieval y moderna en el área mediterránea occidental, resultado de las investigaciones de un grupo con amplia trayectoria en este tema y su presentación en reuniones científicas preparatorias, como la de Mazarrón de 2015. En cuanto a la metodología seguida, aunque los trabajos se apoyan principalmente en fuentes documentales diversas (protocolos notariales, información fiscal, expedientes judiciales, recetarios, etc.), resulta muy interesante el capítulo inicial (Dallai y Martínez), que aborda el estado de la reconstrucción de las explotaciones, desde el punto de vista arqueológico, en dos ámbitos geográficos diferentes: Toscana y Murcia.

Aunque algunos estudios se centran en el periodo medieval (Basso) o se extienden hasta finales del siglo xvi (García-Contreras), el contexto en que se enmarcan la mayoría las contribuciones está vinculado al periodo comprendido entre mediados del siglo xv y comienzos del siglo xvI, una época caracterizada por la recuperación económica en buena parte de Europa, donde crecen las industrias textiles que demandan este producto, esencial para el teñido de los paños, pero también para otros usos y actividades como el curtido, la soldadura y coloreado de metales, la coloración y tinta de manuscritos, así como otras aplicaciones en el vidriado o incluso la higiene y el cuidado personal que se observan a través de los recetarios técnicos de la época (Córdoba de la Llave). No obstante, el textil es el principal foco de la demanda y el norte de Europa (Flandes, Inglaterra) el destino principal de los alumbres mediterráneos, lo que genera un intenso y lucrativo comercio donde los italianos desempeñan un papel esencial.

Los problemas relacionados con la tradicional fuente de provisión de alumbres, que era la zona de Asia Menor y el Mediterráneo Oriental, ocasionados por el descenso de producción de algunos yacimientos y el control de la zona por los turcos otomanos, dio pie a la búsqueda y explotación de zonas alternativas situadas. Principalmente en Italia, donde se comenzaron a explotar los yacimientos de Toscana, Nápoles y, sobre todo, el de Tolfa, situado en los dominios papales, pero también en España, con las concesiones regias para la explotación en la Corona de Castilla de los yacimientos de Mazarrón y Cartagena en Murcia (Munuera), así como el de Rodalquilar y otros lugares en Almería (García-Contreras).
Las concesiones de estas minas, que probablemente ya habían sido explotadas en épocas anteriores, se hicieron entre mediados del siglo xv y comienzos del xvi a personajes vinculados con la Corona, como el marqués de Villena, el marqués de los Vélez, Francisco de Vargas o Francisco de los Cobos. Estos arrendaban a negociantes la explotación del mineral, cuya obtención seguía un complejo proceso con varias fases y operaciones técnicas, el uso masivo de recursos como agua y combustible vegetal y el empleo de mano de obra que requirió su establecimiento permanente en asentamientos fundados junto a estos yacimientos. Al mismo tiempo, la localización geográfica de algunos yacimientos, cercana a la costa, como el de Mazarrón o el almeriense de Rodalquilar, obligó a la construcción de torres de defensa para protegerse de las incursiones berberiscas. La aportación sobre la reconstrucción arqueológica de la explotación de Monteleo en la Toscana y la de Mazarrón (Dallai y Martínez) permiten comprender mejor tanto los procesos técnicos en las zonas de extracción y elaboración como las verdaderas dimensiones físicas de este tipo de actividades a lo largo del tiempo y la infraestructura complementaria que requerían.

También en la Corona de Aragón se localizan y explotan diversos yacimientos, como los que se refieren a los territorios valencianos y aragoneses (Navarro y Villanueva), aunque de entidad mucho menor que los murcianos o almerienses. De hecho, los datos fiscales de las aduanas aragonesas que se aportan en su estudio muestran un comercio de alumbre donde las entradas superan con mucho a las salidas, en un comercio en el que intervenían trajineros mudéjares y pequeños negociantes poco especializados.

En varios de los trabajos se refleja que el negocio estaba sujeto a rivalidades y conflictos entre los concesionarios de las minas y los comerciantes arrendatarios, que intentaban controlar el mercado y evitar la caída de precios con medidas como reducir la producción aún a costa de cerrar explotaciones -Rodalquilar, por ejemplo-, aunque tiene una fase de recuperación posterior en la segunda mitad del siglo xvi (García-Contreras). Los negociantes italianos dominaban las redes del tráfico de los alumbres en la zona mediterránea y llegaban incluso a tratar directamente con los propios artesanos la provisión del producto, como se refleja en el caso de la industria textil rural valenciana (Llibrer). Asimismo, controlaban las redes de suministro exteriores, como la ruta hacia Flandes, donde a veces participaron comerciantes y navieros castellanos, como se observa para el caso de Mazarrón, pero también en el interior, como se ilustra en el comercio del alumbre de Rodalquilar en la provisión de los mercados andaluces.

Las prácticas monopolísticas de las compañías, los intereses de los propietarios como el caso de la Santa Sede en Tolfa y la coyuntura internacional se mezclaban en un negocio que fue en determinados periodos muy lucrativo para sus princi- 
pales agentes, caso del negociante sienes Agostino Chigi a comienzos del siglo xvi, cuando obtuvo prácticamente una situación de monopolio en el negocio de los alumbres controlando los yacimientos más importantes de Italia y España (Ait, Boisseuil e Igual). Sin embargo, en otras ocasiones las fases de bonanza se sucedían a las de quiebras y dificultades financieras de las compañías arrendatarias, como sucede en Rodalquilar.

Por todo ello resulta pertinente enmarcar esta coyuntura en un panorama más amplio en el tiempo y el espacio, integrando las diferentes facetas del negocio del alumbre. En este sentido, el trabajo de Basso pone en evidencia el papel crucial de los genoveses en el comercio del alumbre en los siglos medievales, combinando los elementos de política internacional a través de los acuerdos que establecen con las monarquías para la circulación y suministro del producto, la adaptación y mejora de técnicas de construcción de embarcaciones y condiciones de navegación para adecuarse a los requerimientos de las cargas y las rutas del tránsito, así como la incorporación de nuevas técnicas comerciales y societarias que se exigían en este negocio, como es el caso del seguro marítimo. Los negociantes genoveses mantuvieron un papel preponderante en la explotación y comercio de los alumbres dominando este mercado hasta bien entrado el siglo xvI, junto a otras múltiples actividades comerciales y financieras que desarrollaron en esta época.

En suma, esta contribución colectiva añade interesantes datos a uno de los productos mejor conocidos en cuanto a su producción y comercialización durante este periodo. Se completa, además, con un resumen general, una detallada bibliografía e índices onomásticos y toponímicos. La combinación de la documentación con la reconstrucción arqueológica ofrece nuevas posibilidades y permitiría abordar nuevos problemas ligados al proceso productivo, como el uso de recursos (agua, combustible) y el impacto sobre el paisaje.

José U. Bernardos Sanz Universidad Nacional de Educación a Distancia 